\title{
Diagnosis of Caprine Brucellosis by Serology and Multiple PCR
}

\author{
Raúl A. Cuevas-Jacquez ${ }^{1}$, José L. Ortega-Sánchez², \\ Maribel Cervantes-Flores ${ }^{4}$, Rebeca Pérez-Morales ${ }^{l}$, Sandra I. Hernández-González ${ }^{l}$, José J Alba-Romero ${ }^{1,3}$, \\ Aurora Martínez-Romero ${ }^{1,1}$ \\ ${ }^{1}$ Laboratorio de Investigación, Facultad de Ciencias Químicas (FCQ) Campus Gómez Palacio, Universidad \\ Juárez del Estado de Durango (UJED), Durango (Dgo.), México. \\ ${ }^{2}$ Unidad Regional Universitaria de Zonas Áridas. Universidad Autónoma Chapingo, Dgo. \\ ${ }^{3}$ Laboratorio de Asesores Especializados de la Laguna, Gómez Palacio, Dgo. \\ ${ }^{4}$ FCQ, Campus Durango Laboratorio de Inmunología e Infectología. UJED. Dgo.
}

\begin{abstract}
Our aim was to perform the diagnosis of caprine brucellosis by serology and multiple Polymerase Chain Reactions (PCR). The field work was conducted on the Ejidos la Victoria MunicipioTlahualilo Public Lands of San José de Bellavista y Bermejillo, Mapimí Municipality, state of Durango, Mexico. Meetings were held with the producers to explain to them the objectives and benefits to be obtained with the carrying out of this investigation. Samples were taken from 114 native breed animals crossed with Saanen and Alpine breed animals from the jugular vein, obtaining 114 blood samples in tubes without anticoagulant for the obtention of serum in order to process the Rose Bengal Plate Test (RBPT) and 114 whole blood samples for processing multiple PCR. We carried out DNA extraction of control strains of Brucella abortus RB51 and Brucella melitensis RMI employing the phenol:chloroform:isoamyl alcohol method with the oligonucleotide sequence of Brucella genus, Brucella abortus, Brucella melitensis, Brucella suis, and IS711. General seroprevalence was $26.31 \%$ and seroprevalence by Tlahualilo Municipality was $41.86 \%$, while this in Mapimi was $18.18 \%$. In the multiple PCR sample analysis, we found that 30 samples corresponded to B. melitensis, obtaining 100\% sensitivity and specificity. The PCR technique described in this study presented 100\% sensitivity and specificity with the RBPT, allowing for the simultaneous identification, between and genus and species, the implementation of the multiple-PCR variant capable of identifying different species of the Brucella genus, the latter leading to a better diagnosis of the disease.
\end{abstract}

Keywords: Brucella melitensis, goats, sensitivity, specificity.

\section{Introduction}

Brucellosis is cataloged as a bacterial zooonosis found worldwide whose genus is Brucella and that consists of multiple species [1]. Its incidence ranges from between 1.3 and 70.0 cases per 100,000 inhabitants, differences due to the characteristics of each nation. Mexico is one of the countries with the greatest incidence of human brucellosis in Latin America, causing economic loses generated in domestic cattle-raising and its impact on public health [2]. The highest brucellosis incidence rates were found in bovines, followed by caprines and ovines. The genus Brucella includes three important species for human pathology: Brucella melitensis, which preferentially affects goats, but that can affect bovines and pigs. In Mexico, the highest incidence of bovine brucellosis is observed in stabled livestock and in high-animal-density areas, such as the central, southeastern, and coastal zones. Caprine brucellosis possesses a wider distribution with greatest frequency registered in entities with high goat concentrations [3].

At present, the Mexican Ministry of Health carries out educative health activities, informing the population of the public health problem represented by the consumption of non-pasteurized lactic products and contact with the meat of animals suffering from brucellosis. Preventive measures for professional risk include the following: consume pasteurized milk, subproducts, and derivatives of these, rejecting those of doubtful origin; limit close cohabitation with animals; wash hands with soap and water before eating and after contact with animal or subproducts and waste; cleanliness, disinfection, and separation by means of fences in places for the raising/breeding of livestock (caprine, bovine, and porcine); identification and elimination of sick animals and vaccination prior to 3 months of age; timely stimulation of medical care and treatment termination; motivation of the medical and paramedical area to conduct patient follow-up at 30,60,90, and 120 days, and maintain surveillance of blood donors being brucellosis-negative [4].

Maximal focus cases have been reported of up to $18.3 \%$ of brucellosis in humans, caused by the ingestion of caprine- and ovine-origin lactic products in which B. abortus and B. melitensis were involved.

\footnotetext{
${ }^{1}$ Correspondencia: E-mail: quimicaaurora@ hotmail.com Articulo 123 s/n Colonia Filadelfia, Gómez Palacio, Durango, México

DOI: 10.9790/2380-1005018287 $\quad$ www.iosrjournals.org $\quad 82 \mid$ Page
}


Mexico places worldwide as one of the regions with the greatest prevalence of bovine brucellosis, with $3.42 \%$ seropositivity in humans. In the Mexican state of Zacatecas, the campaign against brucellosis is found in the control phase. Brucellosis prevalence at the domestic level in herds/flocks was $2.94 \%$ and $0.61 \%$ in heads of cattle; thus, it is referred that caprine brucellosis was determined as $10.35 \%$, and for ovine brucellosis, this was $0.61 \%$ for the same year [5].

Reinforcing zoosanitary status has repercussions on public health, in that it mitigates the risk of contagion in humans due to the consumption of unpasteurized lactic products[6]. The Comarca Lagunera is a brucellosis-endemic zone, and this disease tends toward chronicity due to ignorance in terms of its diagnosis, treatment, and implications for public health, in that it causes arthritis, endocarditis, meningitis, and osteomyelitis, while it also leads great economic losses on being a zoonosis.

In that brucellosis is a zoonosis, it is economically important for humans and livestock, and its worldwide distribution is caused by Gram-negative bacteria, facultative intracellular, that belongs to the genus Brucella. The identification and differentiation of Brucella species is based on the culture, a long and laborious process, in addition to there being a risk of infection. Although the serodiagnosis of brucellosis is performed by means of the detection of specific antibodies, it is necessary to confirm the result with molecular methods. Therefore, the study of novel techniques that improve the diagnosis of this disease is fundamental.

In addition, there is scarce information on the relative knowledge of the blood profile in goats with brucellosis; thus, it is pertinent to know the changes among the biochemical and hematological metabolites that can reflect the effects of brucellosis on animal health. Because with a zoonosis, it is essential to know the hematological and blood biochemical values, in that they are indispensable indicators for carrying out diagnostic health evaluations at the individual as well as at the population level. Having access to reference data supplied by healthy persons contributes to the early detection of individual diseases and/or organic dysfunctions. Therefore, the objective of the present investigation was to perform a comparison between the serological and molecular method in the diagnosis of brucellosis with multiple PCR multiple in healthy bovine cattle and in those with brucellosis.

\section{Type, place of study, and ethical aspects}

\section{Materialsand Methods}

The present analytical study was approved by the Research Ethics Committee of the FCQ of the University of the State of Durango (UJED) N¹23301538X0201 COFEPRIS. The field work was carried out in the Ejidos la Victoria MunicipioTlahualilo Public Lands, San José de Bellavista y Bermejillo, Mapimí Municipality, state of Durango, Mexico. Meetings were held with the producers to explain the objectives and benefits to be obtained with the performance of this investigation. The sampling was consecutive in gestating goats 12 months of age with and without brucellosis. We collected approximately $10 \mathrm{~mL}$ of blood per goat; sampling was conducted in tubes ${ }^{2,3}$, and immediately afterward, the tubes were transported in coolers for their processing. The serum was separated from the blood by centrifugation ${ }^{4}$ at 3,000 rpm during 10 min.

Each sample was labeled utilizing codes that described each animal. One hundred fourteen native goats crossed with Saanen and Alpine breeds were sampled by the jugular vein, obtaining blood samples in a tube with anticoagulant to obtain the serum for processing by means of the RBPT ${ }^{5}$ at the Regional University Unit of Arid Zones (URUZA) of the Autonomous University of Chapingo (UACh) and 114 samples of whole blood for multiple PCR processing at the FCQ, Durango Unit, UJED. We carried out DNA extraction of the control strains of Brucella abortus RB51 and Brucella melitensis RM1 employing the phenol:chloroform:isoamyl alcohol method with two wrinkled B. abortus RB51 and B. melitensis RM1 control strains, with the oligonucleotide sequence of Brucella genus (BG), Brucella abortus (BA), Brucella melitensis (BM), Brucella suis (BS), and IS711 (IS). Meetings were held for the producers to explain the objectives and benefits to be obtained with the performance of this investigation. We performed multiple PCR applying this to each of the samples: Identification of Brucella spp. was based on the amplification of the genomic region of the $b \operatorname{csp} 31^{6}$ gene. The DNA sequence constituted by the animals' feeders [7] is shown in table 1.

\section{DNA extraction of control strains}

To carry out the genomic extraction of the control strains of Brucella, this began from a 5-day growth in Trypticase Soy Agar (TSA) broth. We placed $1.5 \mathrm{~mL}$ of culture in an Eppendorf tube and centrifuged this for $2 \mathrm{~min}$ at 13,000 rpm. The supernatant was eliminated and the cellular pellet was resuspended in $1 \mathrm{~mL}$ of lysis

\footnotetext{
${ }^{2}$ BD Vacutainer® Suero/SERUM $13 \times 100 \mathrm{~mm}$.

${ }^{3}$ BD Vacutainer ${ }^{\circledR}$ K2E/K2 EDTA $13 \times 75 \mathrm{~mm}$.

${ }^{4}$ SOLBAT ${ }^{\circledR}$ Modelo C-600, México.

${ }^{5}$ ABA test card at $3 \%$ Brucella Abortus Antigen (BAA), PRONABIVE ${ }^{\circledR}$ México.

${ }^{6}$ GenBank access \#M20404.
} 
buffer (EDTA $50 \mathrm{mM}, \mathrm{NaCl} 100 \mathrm{mM}, \mathrm{pH}$ 7.5), was mixed in a vortex until resuspension, and was centrifuged for $2 \mathrm{~min}$ at 13,000 rpm to recover the bacterial pellet again and the supernatant was eliminated. To recover this, we resuspended this again in $300 \mu \mathrm{l}$ of lysis buffer. After this, we added $100 \mu \mathrm{l}$ of lysozyme $(10 \mathrm{mg} / \mathrm{mL}) \mathrm{drop}-$ by-drop and shook this with a vortex; the mixture was incubated for $15 \mathrm{~min}$ at $37^{\circ} \mathrm{C}$. We added, to the cellular extract, $30 \mu \mathrm{L}$ of Sodium DiSulfate (SDS) at $20 \%$ and incubated this at $37^{\circ} \mathrm{C}$ during $5 \mathrm{~min}$. We extracted the lysate with a similar volume of phenol-chloroform-isoamyl alcohol (24:25:1) u/u; this was mixed and centrifuged at 13,000 rpm for $5 \min (206.4: 215: 8.67 \mu \mathrm{L})$ [8]. The aqueous phase was transferred, we added 30 $\mu \mathrm{L}$ of sodium acetate $3 \mathrm{M}$, and filled the tube with cold ethanol at $95 \%$. We inverted the tube, observing that the chromosomic DNA formed a pellet. The DNA was left to dry and later was resuspended in nuclease-free water. Finally, we proved the presence and integrity of the DNA in agarose gel 1\% stained with Ethidium Bromide (EtBr) $0.5 \mathrm{mg} / \mathrm{mL}$, after having submitted it to electrophoresis $(120 \mathrm{~V} / 208 \mathrm{~mA})$ in a Tris-Acetate-EDTA (TAE) $1 \mathrm{X}$ buffer. DNA concentration and purity were calculated in NanoDrop ${ }^{\mathrm{TM}^{7}}$ by means of a 260/280 ratio.

\section{Extraction of genomic DNA in whole blood}

Extraction of genomic DNA in whole blood consisted of placing $500 \mu \mathrm{l}$ of whole blood in an Eppendorf tube, to which we added $1 \mathrm{~mL}$ of red-blood lysis solution, $0.01 \mathrm{M}$ Tris- $\mathrm{HCl} \mathrm{pH} 7.6,320 \mathrm{mM}$ sucrose, $5 \mathrm{mM} \mathrm{MgCl}_{2}$, and $1 \%$ Triton $\mathrm{X} 100^{8}$. This was centrifuged at 7,000 rpm for $2 \mathrm{~min}$, the supernatant was discarded, and this step was repeated two or three times until we observed no excess of hemoglobin. We added $400 \mu \mathrm{l}$ of nucleic-acid lysis solution $(0.01 \mathrm{M}$ Tris-HC1, $11.4 \mathrm{mM}$ sodium citrate, $1 \mathrm{mM}$ EDTA, and $1 \%$ of SDS). We then added $100 \mu \mathrm{L}$ of $\mathrm{NaCl}(5 \mathrm{M})$ and $600 \mu \mathrm{L}$ of $\mathrm{CHCl}_{3}$; this was centrifuged at 7,000 rpm for $2 \mathrm{~min}$ and we transferred $400 \mu \mathrm{L}$ of the supernatant into a new tube. We added to this $800 \mu \mathrm{L}$ of cold absolute ethanol $\left(-20^{\circ} \mathrm{C}\right)$, vortexed it, and afterward, centrifuged it for $1 \mathrm{~min}$ at $12,000 \mathrm{rpm}$. Finally, we added $50 \mu \mathrm{L}$ of $\mathrm{TE}$ to conserve the DNA at $4{ }^{\circ} \mathrm{C}$ until its use. The DNA integrity was observed in agarose gel at $1 \%$ stained with EtBr $0.5 \mathrm{mg} / \mathrm{mL}$ after having been submitted to electrophoresis $(120 \mathrm{~V} / 208 \mathrm{~mA})$ in a TAE $1 \mathrm{X}$ buffer. DNA concentration and purity was calculated in NanoDrop $^{\mathrm{TM}}$ by means of a 260/280 ratio.

\section{Conditions of multiple PCR}

Multiple PCR was carried out in the whole blood samples as well as in the genomic DNA of the strain. This was performed in a total volume of $25 \mu \mathrm{L}$ of reaction that contained the following: $5 \mu \mathrm{L}$ of PCR buffer reaction; $0.2 \mathrm{mM}$ of each deoxyNucleotideTriPhosphate (dNTP), and $1.5 \mathrm{mM}$ of $\mathrm{MgCl}_{2}$. The feeders were mixed at concentration of $800 \mathrm{nM} \mathrm{BG-F}$ and -R, $600 \mathrm{nM}$ of IS, $350 \mathrm{nM}$ of Brucellaabortus (BA), $450 \mathrm{nM}$ of BrucellaSuis(BS), and $200 \mathrm{nM}$ of Brucellamelitensis(BM). We added, for each reaction, $2 \mu \mathrm{L}(\sim 500 \mathrm{pg})$ of DNA template and $1 \mathrm{U}$ of Taq polymerase [7].

Amplification consisted of an initial denaturalization at $95^{\circ} \mathrm{C}$ during $1 \mathrm{~min}, 30$ amplification cycles with denaturalization at $95^{\circ} \mathrm{C}$ during $5 \mathrm{sec}$, hybridation at $64^{\circ} \mathrm{C}$ during $10 \mathrm{sec}$, extension at $72^{\circ} \mathrm{C}$ during $30 \mathrm{sec}$, and a final extension at $72^{\circ} \mathrm{C}$ during $1 \mathrm{~min}$ in the thermocycler ${ }^{9}$. The presence and integrity of the genomic DNA of the PCR products were proven in agarose gel $1 \%{ }^{10}$, stained with EtBr $0.5 \mathrm{mg} / \mathrm{mL}$ after having been submitted to electrophoresis $(120 \mathrm{~V} / 208 \mathrm{~mA})$ in a TAE $1 \mathrm{X}$ buffer.

\section{Results}

General seroprevalence was $26.32 \%$, and for Tlahualilo Municipality this was $41.86 \%$, while in Mapimí it was $18.18 \%$. We observed the band pattern of the strains of each species. We carried out the determination of DNA concentration and purity obtained employing NanoDrop ${ }^{\mathrm{TM}}$ equipment, the results of which were as follows: for the B. melitensisRM1 strain, there was a concentration of $149 \mathrm{ng} / \mu \mathrm{L}$ and 1.7 purity in the $260 / 280$ ratio, while for the $B$. abortus RB51 strain, there was a concentration of $120 \mathrm{ng} / \mu \mathrm{L}$ and 1.7 purity.

\section{ExtractionofGenomic DNA of Whole-blood Samples}

The application of multiple PCR in this study required having an adequate DNA-extraction method of blood samples, due to that Brucella is an intracellular-growth microorganism it is fundamental for the bacterial DNA (if it were to exist in the sample) to be extracted from the interior of the macrophage which is where it inhabits, in the most integral form possible and at concentrations that are adequate for performing its later amplification. We observed an average concentration of $230 \mathrm{ng} / \mu \mathrm{L}$ with a Standard Deviation (SD) of 15.7 and 1.63 purity with an SD of 1.5 in the 260/280 ratio, which permitted us to perform amplification of the samples.

\footnotetext{
${ }^{7}$ ThermoScientificNanoDrop ${ }^{\mathrm{TM}} 2000^{\circledR}$, USA.

${ }^{8}$ Sigma-Aldrich ${ }^{\circledR}$, USA.

${ }^{9}$ MyCycler,Bio-Rad ${ }^{\circledR}$, USA.

${ }^{10}$ Agarose, LE, Analyticalgrade, Cat. \# V3125 Promega ${ }^{\circledR}$, Spain.

DOI: 10.9790/2380-1005018287 $\quad$ www.iosrjournals.org $\quad 84 \mid$ Page
}




\section{Multiple PCR}

We carried out DNA amplification of the control strains to determine their band pattern. We observed that the band that defined the genus Brucella determined by feeders of the bcsp 31 gene genomic region presents $208 \mathrm{pb}$, while bands of the species B. abortusand B. melitensis that are determined by the feeders that are directed to the specific integration of element IS711 in the genome of the respective species evidenced the $B$. melitensis species in the 731-pb band and the B. abortus species, in the 498-pb band (figure 1).

On analysis of the samples that were RBPT-positive, on processing the multiple PCR, we found that these samples corresponded to B. melitensis with a 731-pb band (figure 2).

\section{Sensitivity and Specificity of the Multiple PCR Technique for Diagnosis of Brucellosis}

To determine the sensitivity and specificity of the multiple PCR technique, we employed the Odds Ratio (OR) statistical method, utilizing BR as the standard diagnostic test. On applying the $2 \times 2$ table, we obtained the sensitivity, specificity, Positive Predictive Value (PPV), and Negative Predictive Value (NPV) described in tables 2 and 3 .

\section{Discussion}

At present, there are specific diagnostic methods of brucellosis, including serological, molecular, or microbiological methods, and RB continues to be utilized as a diagnostic test [9]. Molecular tests permit us to know the species of the genus Brucella. Diverse authors have reported techniques for the molecular diagnosis through PCR and have cited its high sensitivity and specificity employing PCR assays in real time. Nagalingam and collaborators in 2012 reported that by means of serological tests, it is not possible to differentiate positive brucellosis in infected and in vaccinated animals; however, through the multiple PCR technique, it is possible to differentiate between vaccine strains S19, RB51, and Rev1 and infecting strains of the genus Brucella of livestock and humans [10]. In this study, multiple PCR was carried out in whole blood samples, such as the genomic DNA of the strain, conditions that have already been considered in the identification of the genus and species of Brucella, on which multiple PCR was performed directly from clinical samples, affording certainty to the diagnosis. In this respect, it has been determined that the identification of Brucella spp. by conventional tests involve time, risk, and requires interpretation by an expert, while the PCR technique is rapid, sure, and easy to interpret. In the present investigation, 30 serum samples were confirmed as positive for RBPT, and from the same sampling with 30 samples of whole blood, the isolation was confirmed of B. melitensis with multiple PCR. In the same manner, Irajian et al. analyzed 68 isolations by PCR from humans as well as from animals, among which B. melitensis predominated in 36 isolates, two of B. abortus and one of B. suis of the animal specimen, and 24 isolates of B. melitensis and six of B. abortus of the human specimen [8]. In this regard, it was documented that $B$. melitensis presents very severe clinical conditions in humans [2].

In the present work, in the results of the amplification of the RBPT-negative samples, bands were observed, with which we obtained $100 \%$ sensitivity and specificity; thus, PPV and NPV were $100 \%$. Cevallos and coworkers (2010) also performed a conventional PCR technique, obtaining a sensitivity value of $75 \%$ and one of $92 \%$ for specificity, in comparison with the RBPT technique [11]. On developing the PCR technique utilizing whole blood, it was observed that the technique is fast, that its manipulation is facilitated, and that it diminishes the risk of infection; in addition, it allowed for simultaneous identification of the genus and the species due to the use of the multiple-PCR variant, and it provides overwhelming epidemiological reports due to that it identifies the most prevalent species in a determined population. The latter renders the technique feasible for it to be applied in the diagnostic laboratory.

In addition to the consumption of unpasteurized lactic products, due to which it is necessary to provide technical advice to small producers on the knowledge of brucellosis, of how to prevent the infection in order to not only control the latter, but also to eradicate it from brucellosis-endemic zones. The results of this demonstrate that PCR is an effective method for identifying brucellosis in humans from peripheral-blood samples. Also, PCR could be employed as a rapid and confirmatory instrument for samples for which a doubt arises in terms of RBPT. For future investigations, it is recommendable to utilize multiple PCR for the diagnosis of the different species of the genus Brucella because it amplifies different DIANA sequences, as well as the simultaneous identification of diverse genes. It is recommended to process multiple PCR such as Western blot that detects specific proteins, in that there are cases in which genes are detected that encode for toxins or other virulence factors.

\section{Conclusion}

The multiple PCR technique described in this study can be utilized for the diagnosis of human brucellosis employing whole blood as sample analysis. Also, it possesses a high grade of sensitivity and specificity as a diagnostic test: Its rapidity is noteworthy in addition to that its economy of resources renders it feasible for its application in the diagnostic laboratory. The results demonstrate that RBPT continues to be an 
inexpensive and totally reliable test for performing a good diagnosis of human brucellosis in the absence of PCR for a population with a high level of antibodies in endemic areas.

\section{Acknowledgements}

The authors would like to thank Maggie Brunner for English reviewing of the manuscript.

\section{References}

[1]. Bai Y, Urushadze L, Osikowicz L, McKee C, Kuzmin I, Kandaurov A, et al. Molecular Survey of Bacterial Zoonotic Agents in Bats from the Country of Georgia (Caucasus). PLoS ONE 2017;12:e0171175.

[2]. Méndez-Lozano M, Rodríguez-Reyes EJ, Sánchez-Zambrano LM. Brucelosis, una zoonosis presente en la población: estudio de series de tiempo en México. Salud Pública de México. 2015; 57:519-527.

[3]. Sánchez EO, Ortega JL. Caprine brucellosis seroprevalence in three municipalities of the state of San Luis Potosí, México;2007:141-146.

[4]. SSA. Zoonosis y vectores. Secretaría de Salud. Instituto de Salud del Estado de México. 9 Mayo 2017. salud.edo.mx/html/article.php?sid=332

[5]. SAGARPA. Secretaria de Agricultura, Ganadería, Desarrollo Rural, Pesca y Alimentación. Evaluación Alianza para el Campo 2005. Informe de Evaluación Estatal Subprograma de Salud Animal. 2006. http://www.sagarpa.gob.mx/Delegaciones/zacatecas/Documents/Evaluaciones\%20Externas/2005/Salud\%20Animal\%202005.pdf

[6]. SAGARPA. Secretaria de Agricultura, Ganadería, Desarrollo Rural, Pesca y Alimentación. Servicio Nacional de Sanidad, Inocuidad y Calidad Agroalimentaria. Situación actual. Campaña Nacional contra la brucelosis de los animales NOM-041-ZOO1995. 21 agosto 2015. http://www.senasica.gob.mx/?id=4414

[7]. Irajian GR, Masjedian Jazi F, Mirnejad R, Piranfar V, Zahraei Salehi T, Amir Mozafari N, et al.Species-specific PCR for the Diagnosis and Determination of Antibiotic Susceptibilities of Brucella Strains Isolated from Tehran, Iran. Iran J Pathol2016;11: 238-247.

[8]. Garshasbi M, Ramazani A, Sorouri R, Javani S, Moradi S. Molecular detection of Brucella species in patients suspicious of Brucellosis from Zanjan, Iran. Braz J Microbiol 2014;45:533-538.

[9]. Assenga JA, Matemba LE, Muller SK, Malakalinga JJ, Kazwala RR. Epidemiology of Brucella infection in the human, livestock and wildlife interface in the Katavi-Rukwa ecosystem, Tanzania. BMC Vet Res 2015;11:189.

[10]. Nagalingam M, ShomeR, BalamuruganV, ShomeBR, NarayanaRaoK, Vivekananda, et al. Molecular typing of Brucella species isolates from livestock and human. Trop Anim Health Prod 2012;44:5-9.

[11]. Cevallos-Falquez O, Carranza-PatiñoM, Saucedo-AguiarS, Romero-GaraicoaD, Ramos-GavilanesL, Reyes-ChancayX, et al. Diagnóstico Serológico (Rosa de Bengala) y Molecular (PCR) de Brucelosis en Humano. Ciencia y Tecnología 2010;3:27-32.

Table 1. Primers for detection of Brucella using specific Single Nucleotide Polymorphism (SNP)

\begin{tabular}{|l|l|}
\hline & Sequence 5'-3' \\
\hline Brucella genus & $\begin{array}{l}\text { F: CAATCTCGGAACTGGCCATCTCGAACGGTAT } \\
\text { R: ATGTTATAGATGAGGTCGTCCGGCTGCTTGG }\end{array}$ \\
\hline B. abortus & GACGAACGGAATTTTTCCAATCCC \\
\hline B. melitensis & AAATCGCGTCCTTGCTGGTCTGA \\
\hline B. suis & GCGCGGTTTTCTGAAGGTTCAGG \\
\hline IS711 & TGCCGATCACTTAAGGGCCTTCA \\
\hline
\end{tabular}

Table 2.Use of the $2 \times 2$ table for the evaluation of the diagnostic test.

\begin{tabular}{|l|l|l|l|}
\hline \multirow{2}{*}{ Result of multiple PCR } & Result of RBPT & Total \\
\cline { 2 - 3 } & Positive & Negative & \\
\hline Positive test & 30 & 0 & 30 \\
\hline Negative test & 0 & 84 & 84 \\
\hline Total & 30 & 84 & 114 \\
\hline
\end{tabular}

Table 3.Values of sensitivity, specificity, Positive Predictive Value (PPV), and Negative Predictive Value (NPV).

\begin{tabular}{|l|l|}
\hline & Value (\%) \\
\hline Sensitivity & 100 \\
\hline Specificity & 100 \\
\hline PPV & 100 \\
\hline NPV & 100 \\
\hline
\end{tabular}


a)

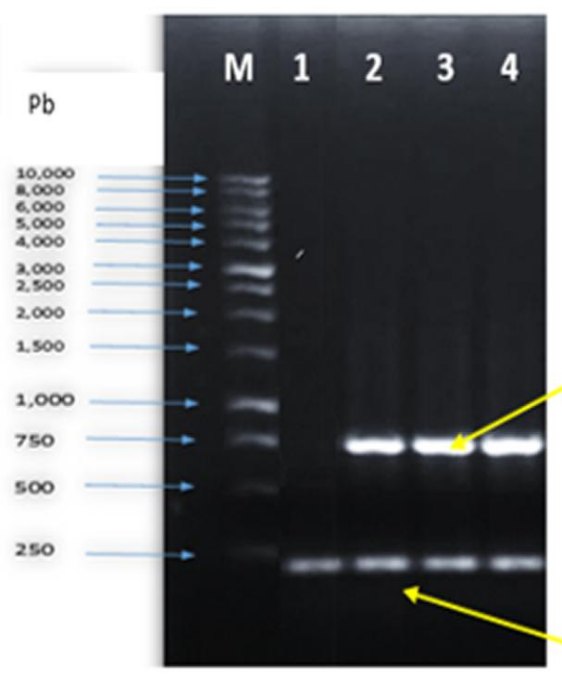

b)

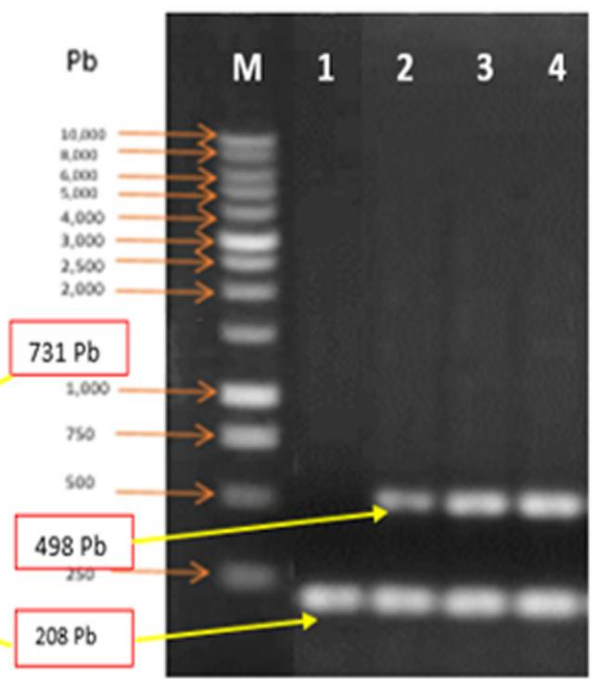

Figure 1.MultiplePolymerase Chain Reaction (PCR) of the control strains. Electrophoresis in agarose gel at $1 \%$, stained with EtBr, showing in $\mathrm{M}$ the molecular weight marker of $\mathrm{Kb}$.

a) Products of the multiple PCR of the control strain of Brucella melitensis RM1. Lane 1: Amplification utilizing solely the genus feeders (with a 208-pb band corresponding to the genus Brucella); Amplification Lanes 2-4 utilizing these genus and species feeders (a >731-pb band corresponding to the species Brucellamelitensis).

b) The multiple PCR products of the control strain of $B$. abortus RB51. Lal.. . : Amplification only utilizing the feeders of the genus (with a 208-pb band corresponding to the genus Brucella); Lanes 2-4, amplification employing feeders of the genus and species (a >498-pbband corresponding to the species B.abortus).

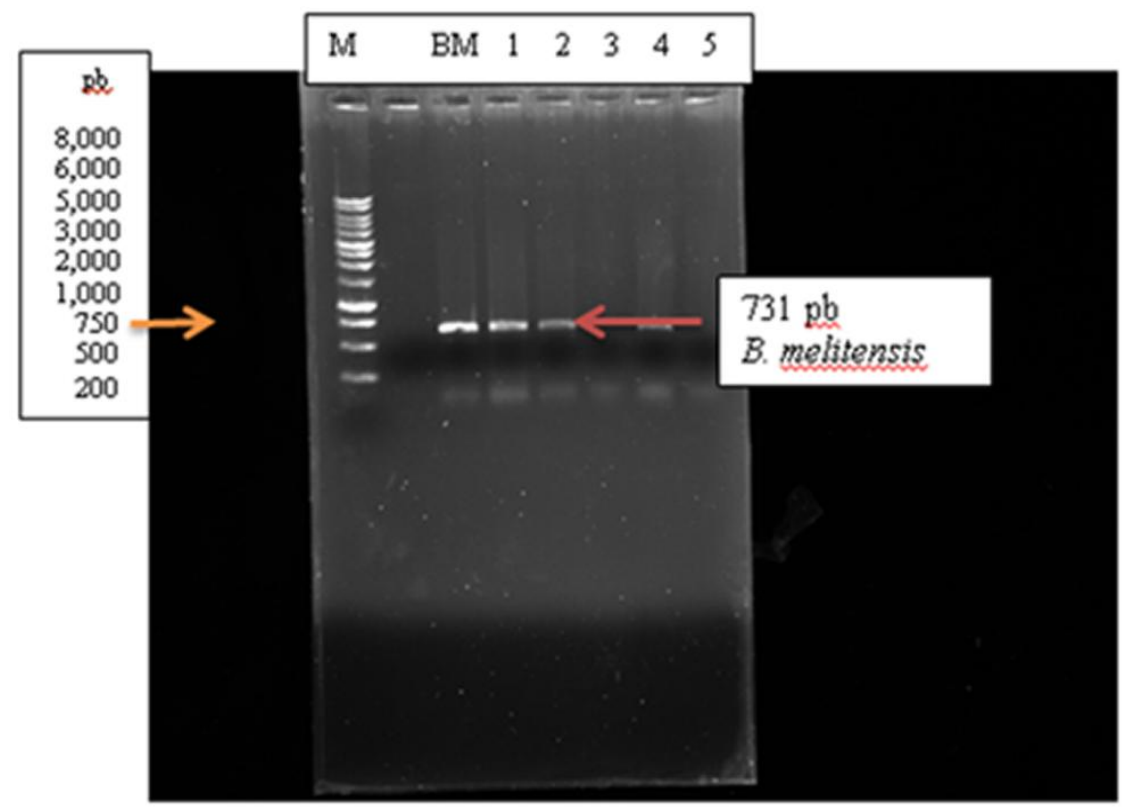

Figure 2. Multiple PCR of Rose Bengal (RB)-positive samples. 